\title{
A tool to estimate the wheel/rail contact and temperature rising under dry, wet and oily conditions
}

\author{
K. D. Vo ${ }^{1,2}$, A. K. Tieu ${ }^{1,2}$, H. T. Zhu ${ }^{1,2}$ \& P. B. Kosasih ${ }^{1}$ \\ ${ }^{I}$ Faculty of Engineering and Information Sciences, \\ University of Wollongong, Australia \\ ${ }^{2}$ Cooperative Research Centre for Railway Engineering and Technology \\ (CRC for Rail Innovation), Australia
}

\begin{abstract}
In this paper, finite element method (FEM) has been applied to evaluate the wheel/rail contact stress under different contact conditions. The elastic-plastic model coded in ANSYS/LS-DYNA includes a whole wheel, $680 \mathrm{~mm}$ of the canted rail, and sub-components of the track (railpads, sleepers, and ballast). The three values of friction coefficient $0.4,0.2$ and 0.07 have been chosen to model the dry, wet and oily environmental contacts, respectively. The high mechanical stresses exerted at the contact area will cause the temperature rise, which results in decreasing of the yield strength of the wheel/rail. The growth of temperature is a major source of the various microstructure changes that occurs on the rail surface, especially the formation of White Etching Layer (WEL). Therefore, a theoretical calculation of heat generation has also been implemented in the current research. The output data from the FEM models have been considered as the input for the theoretical thermal model to examine temperature rising on and beneath the rail surface. The combination of finite element method for contact stress and theoretical thermal method for temperature variation would provide a better understanding about wheel/rail contact under a variety of contact conditions (dry, wet, and oily). Various scenarios of damage mechanisms of rail have been considered in the paper.

The obtained results from the model have revealed that the influence of environmental conditions on normal contact stress, pressure and contact area is negligible. In contrast, the magnitude of the Von-Mises stress and lateral and longitudinal stresses components can be significantly varied depending on the
\end{abstract}


friction conditions. Moreover, the environmental condition has shown a major effect on the temperature rising at the contact zone.

Keywords: finite element method, dry/wet/oil contact, temperature rising.

\section{Introduction}

For effective and economical railway operation, tribological issues must be highly paid attention, especially at the wheel/rail contact surfaces. The severity of the interface processes such as adhesion, wear, rolling contact fatigue (RCF), noise, and heat generation are majorly controlled by the frictional conditions. On the straight track, there is normally one wheel-rail contact regions located on the rail head/wheel tread. However, the contact can also be found at the rail gauge/wheel flange as the wheel rolling on the high rail in a curved track. Ideal friction conditions in the wheel-rail contact regions are proposed as follows [1]:

- Wheel tread-rail head contact: $0.25<\mu<0.4$;

- Wheel flange-rail gauge contact: $\mu<0.1$.

As is well-known, friction at the contact surfaces can be changed depending on the operational situations or environmental conditions. The wheel may contact with the rail at high friction if the two contact surfaces are dry and clean, whereas low friction can be found under wet or oily contact conditions. For instance, Harrison et al. [2] found that the value of friction coefficient under the dry contact was 0.5 and it varied between 0.05 and 0.3 under lubricated condition. The measured coefficients of friction on site and in the laboratory were compared by Olofsson and Telliskivi [3]. For dry contact, the frictional level varied between 0.5 and 0.6 for both on-site and laboratory tests. For lubricated test, the coefficient of friction was decreased to 0.2-0.4. The higher friction, the higher stress will be exerted on the contact surface, which can cause the damage of the wheel/rail [4]. The qualified friction control through the application of friction modifiers to enhance the advantages (adhesion) or to reduce the detriments (wear, RCF) has to be carefully managed.

During the wheel-rail rolling/sliding contact, heat is generated at the contact zone due to friction. The rising of temperature on the wheel-rail surface may soften the material, and affect the strength of the material [5]. Furthermore, the growth of temperature is a major source of the various microstructure changes that occurs on the rail surface, especially the formation of White Etching Layer (WEL) $[6,7]$. This layer is usually generated if the temperature at the contact zone exceeds $700^{\circ} \mathrm{C}$ [8]. Kato et al. [9] found that cracks can be initiated from this white layer, and the initiations of spalling can be reduced with the smaller layer.

The calculation of rolling contact stress has enormously contributed to the anticipation of the damage mechanisms on wheel/rail. However, the comparison of stress states and its thermal influence under a variety of environmental conditions has been rarely discussed in the former publications. In this paper, the elasto-plastic FEM analysis are conducted to reveal the rolling stress states under 
a variety of environmental conditions (dry, wet and oily). The temperature rise of the rail at the contact surface is calculated by a theoretical model. The outputs from the numerical FEM model are considered as the inputs for the analytical thermal model to predict the temperature rise on the rail surface. Moreover, the influence of slip rate on the temperature rise is also taken into account. Based on the obtained results, crack initiation and the formation of White Etching Layer under different contact conditions are also evaluated.

\section{Finite element model of wheel/rail contact}

Among the commercial finite element software, ANSYS/LS-DYNA has shown itself an effective tool to analyse problem associated to contact, large deformations, nonlinear materials, high frequency response phenomenon [10]. Therefore the finite element elastic-plastic model is coded in ANSYS/LS-DYNA in the current study.

The ANZR1 wheel [11] and $60 \mathrm{~kg} / \mathrm{m}$ rail [12] are utilized to construct the models. The wheel/rail profiles are plotted in Pro Engineer and then imported to ANSYS. The model includes a whole wheel, $680 \mathrm{~mm}$ rail which is long enough to cover the distance between two sleepers. Furthermore, the other subcomponents of the track such as railpads, sleepers, and ballast are also included. The FEM mesh of the model is shown in fig. 1, in which very fine mesh can be found at the wheel-rail contact surfaces $(1.3 \times 1.3 \mathrm{~mm})$. The rail is canted an angle of $2.86^{\circ}$ ( 1 in 20 ) according to Australia standard [13].
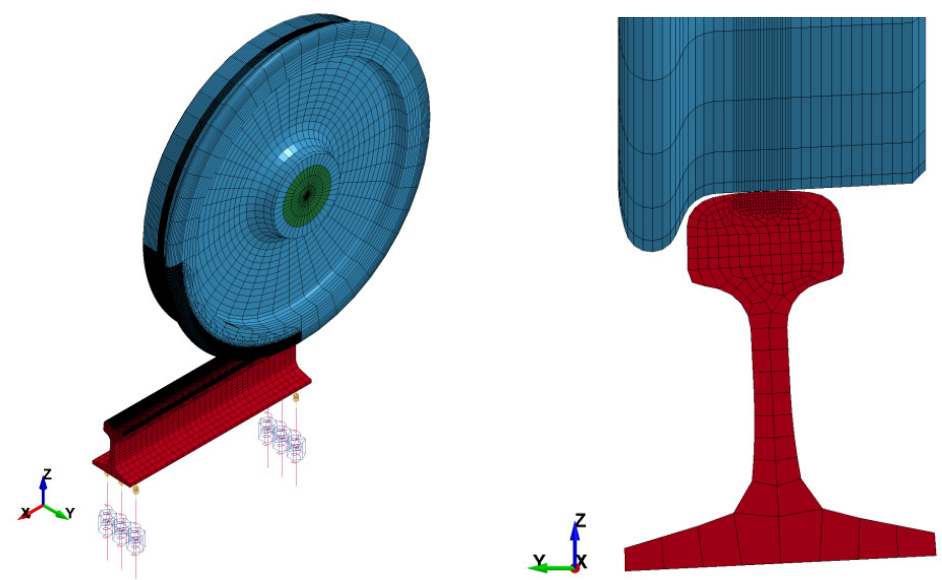

Figure 1: Finite element mesh model.

Different types of element (solid element, mass element, spring and damping element) have been utilized to model the wheel-rail bodies, the sleepers, the railpad and ballast. The wheel is set rolling on the rail under the speed of $80 \mathrm{~km} / \mathrm{h}$, and a normal load of $130 \mathrm{kN}$. Automatic surface to surface contact (ASTS) algorithm has been applied to define the contact between wheel and rail. In order 
to simulate different contact environments, three constant values of friction coefficient which are 0.4, 0.2 and 0.07 have been chosen [4]. For the wet and oily contact, a longitudinal creepage (or also called slip rate $S_{r}$ ) of $1 \%$ has been applied, and two values of longitudinal creepage (1\% and 5\%) are applied for the dry contact. The details of the model can be found in the reference [14].

\section{Analytical thermal method of rail temperature variation}

During the rolling/sliding contact between the wheel and rail, heat is generated at the contact surface due to friction. The temperature rising on and below the rail surface can be obtained theoretically using the following equation [15-17]:

where

$$
\Theta_{\mathrm{r}}(\xi, \zeta)=\frac{\dot{\mathrm{q}}_{\mathrm{r}}}{\beta_{\mathrm{r}}} \sqrt{\frac{2 \mathrm{a}}{v_{\mathrm{r}}}} \mathrm{f}(\xi, \zeta)
$$

$\dot{q}_{r}$, the heat flow rate at the surface of rail;

$\beta_{r}=\sqrt{\lambda \rho c}$, the thermal penetration coefficient of rail;

$v_{r}$, velocity of the rail;

$\left\{\begin{array}{l}\xi=x / a \\ \zeta=z / \delta\end{array}\right.$ are dimensionless coordinates;

- $\quad \mathrm{a}$ is semi-axis in the rolling direction;

- $\delta$ is the thermal penetration depth.

The thermal properties [16] for rail are as follows:

- Thermal conductivity $\lambda=50 \mathrm{~W} / \mathrm{K} \mathrm{m}$;

- Density of the rail $\rho=7800 \mathrm{~kg} / \mathrm{m}^{3}$;

- $\quad$ Specific heat capacity c $=450 \mathrm{~J} / \mathrm{kg} \mathrm{K}$.

At the rail surface, where $\zeta=0$

- For $-1 \leq \xi \leq 1$ (within the contact area)

$$
f(\xi, \zeta)=\sqrt{\xi+1}
$$

- $\quad$ For $\xi>1$ (outside of contact area)

$$
f(\xi, \zeta)=\sqrt{\xi+1}-\sqrt{\xi-1}
$$

Below the rail surface, where $\zeta \neq 0$

- For $-1 \leq \xi \leq 1$ (within the contact area)

$$
f(\xi, \zeta)=\sqrt{\frac{2(\xi+1)}{\pi}} \exp \left[-\frac{\zeta^{2}}{2(\xi+1)}\right]-\zeta \operatorname{erfc}\left[\frac{\zeta}{\sqrt{2(\xi+1)}}\right]
$$


- $\quad$ For $\xi>1$ (outside of contact area)

$$
\begin{gathered}
f(\xi, \zeta)=\left\{\sqrt{\frac{2(\xi+1)}{\pi}} \exp \left[-\frac{\zeta^{2}}{2(\xi+1)}\right]-\zeta \operatorname{erfc}\left[\frac{\zeta}{\sqrt{2(\xi+1)}}\right]\right\}- \\
\left\{\sqrt{\frac{2(\xi-1)}{\pi}} \exp \left[-\frac{\zeta^{2}}{2(\xi-1)}\right]-\zeta \operatorname{erf}\left[\frac{\zeta}{\sqrt{2(\xi-1)}}\right]\right\}
\end{gathered}
$$

The denotation $\operatorname{erfc}$ is called the complementary error function. The details of equations (2)-(5) can be found in the literature [16]. Outputs of FEM model (dimension of contact zone, contact pressure, slip rate) are considered as inputs of analytical thermal model to calculate the temperature rising on and below the rail surface under different contact conditions.

\section{Results and discussions}

In this part, the stress analysis from the finite element model and the temperature distribution from the analytical thermal model under different environmental contact (dry, wet, and oily) will be discussed in details.

\subsection{Wheel-rail contact stress}

To validate the proposed FEM wheel/rail contact model, the normal and traction forces under different friction conditions and the same creepage $\left(S_{r}=1 \%\right)$ is compared with those from CONTACT software developed by Kalker [18]. It can be found in Table 1 that FEM models are in good agreement with CONTACT models. The value of traction force in the dry contact is the highest $(51.51 \mathrm{kN})$; whereas it has been decreased to $25.44 \mathrm{kN}$ in the wet contact and $8.47 \mathrm{kN}$ in the oily contact.

Table 1: Contact forces between wheel/rail $\left(\mathrm{S}_{\mathrm{r}}=1 \%\right)$.

\begin{tabular}{|c|c|c|c|c|}
\hline \multirow{2}{*}{ Contact condition } & \multicolumn{2}{|c|}{ Normal force $(\mathrm{kN})$} & \multicolumn{2}{c|}{ Traction force $(\mathrm{kN})$} \\
\cline { 2 - 5 } & FEM & CONTACT & FEM & CONTACT \\
\hline Dry $(\mathrm{COF}=0.4)$ & 130.5 & 130.0 & 51.51 & 51.98 \\
\hline Wet $(\mathrm{COF}=0.2)$ & 130.9 & 130.0 & 25.44 & 26.00 \\
\hline Oil $(\mathrm{COF}=0.07)$ & 130.4 & 130.0 & 8.47 & 9.10 \\
\hline
\end{tabular}

Fig. 2 shows the contours of the contact pressure and the contact shear stress on the rail surface under the dry contact $\left(\mathrm{S}_{\mathrm{r}}=1 \%\right)$. As illustrated in the figure, the shape of the contact patch is elliptical and the highest contact stress is located at the centre of the contact zone. The maximum values of contact pressure and contact shear stress under this contact condition is $1168 \mathrm{MPa}$ and $462 \mathrm{MPa}$ respectively. 


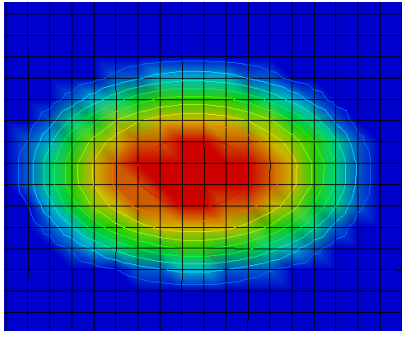

(a) Contact pressure

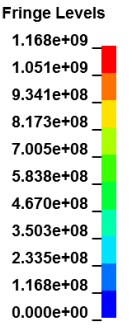

$0.000 \mathrm{e}+00$

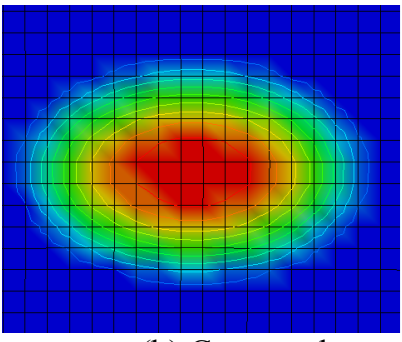

Fringe Levels $4.627 \mathrm{e}+08$ $4.165 \mathrm{e}+08$ $3.702 \mathrm{e}+08$ $3.239 \mathrm{e}+08$ $2.776 \mathrm{e}+08$ $2.314 \mathrm{e}+08$ $1.851 \mathrm{e}+08$ $1.388 \mathrm{e}+08$ $9.255 \mathrm{e}+07$ $4.627 \mathrm{e}+07$ $0.000 \mathrm{e}+00$

(b) Contact shear stress

Figure 2: Contact pressure and shear stress distribution (dry, $\mathrm{S}_{\mathrm{r}}=1 \%$ ).

The summary of contact pressure and contact shear stress for different friction condition is presented in the Table 2. It is interesting to note that the environmental condition and slip rate have minor effects on the maximum contact pressure and the contact area. For instance, the contact area in the wet contact is $204 \mathrm{~mm}^{2}$ which is almost equal to that in the oily contact $\left(205 \mathrm{~mm}^{2}\right)$. Nevertheless, the value of shear stress varies significantly to the changing of environmental conditions. In particular, the highest shear stress found in the dry condition is $462 \mathrm{MPa}$. This value has been decreased to $229 \mathrm{MPa}$ and $77 \mathrm{MPa}$ in the cases of wet and oily contacts, respectively. It can be confirmed that environmental conditions (or the friction control) has played important role to govern the shear stress. The higher friction, the higher shear stress may be produced on the wheel-rail contact zone.

Table 2: Summary of contact pressure and contact shear stress.

\begin{tabular}{|c|c|c|c|}
\hline \multirow[b]{2}{*}{ Parameter } & \multicolumn{3}{|c|}{ Contact conditions } \\
\hline & $\begin{array}{c}\text { Dry } \\
(\mathrm{COF}=0.4)\end{array}$ & $\begin{array}{c}\text { Wet } \\
(\mathrm{COF}=0.2)\end{array}$ & $\begin{array}{c}\text { Oil } \\
(\mathrm{COF}=0.07)\end{array}$ \\
\hline $\mathrm{A}, \mathrm{mm}^{2}$ & 209 & 204 & 205 \\
\hline Pmax, MPa & 1167 & 1162 & 1166 \\
\hline $\mathrm{Tmax}, \mathrm{MPa}$ & 462 & 229 & 77 \\
\hline
\end{tabular}

The contours of Von-Mises stress distributions on the rail and the cross section are plotted in fig. 3. Under three different contact conditions, the highest Von-Mises stress is achieved in the dry contact (799 MPa), and such stress has been reduced to $731 \mathrm{MPa}$ in wet contact and $716 \mathrm{MPa}$ in oily contact. Furthermore, the maximum stress lies at the contact surface and penetrates to $2.6 \mathrm{~mm}$ below the rail surface. In contrast, the maximum stress in the cases of wet and oily contact place $2.2 \mathrm{~mm}$ below the rail surface. The similar tendency of the Von-Mises stress distribution at dry contact is reported in [19]. 
It can be predicted that under this wheel-rail contact load condition, damage may be initiated at the surface in the dry contact, whereas it is likely originated below the contact surface in the wet and oily contact conditions.
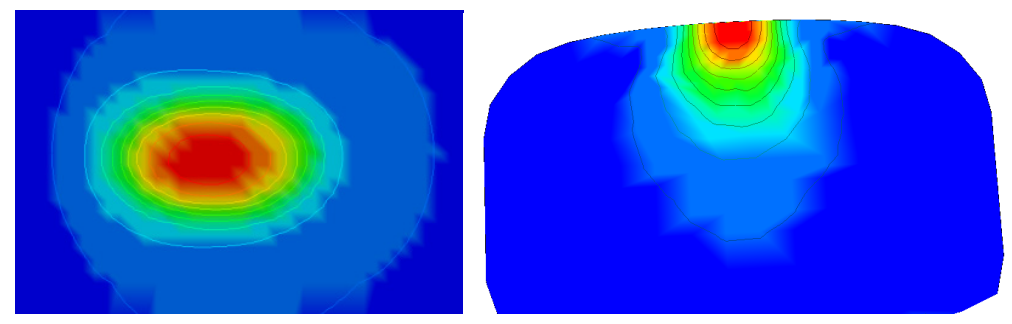

(a) Dry contact, $\mathrm{S}_{\mathrm{r}}=1 \%$
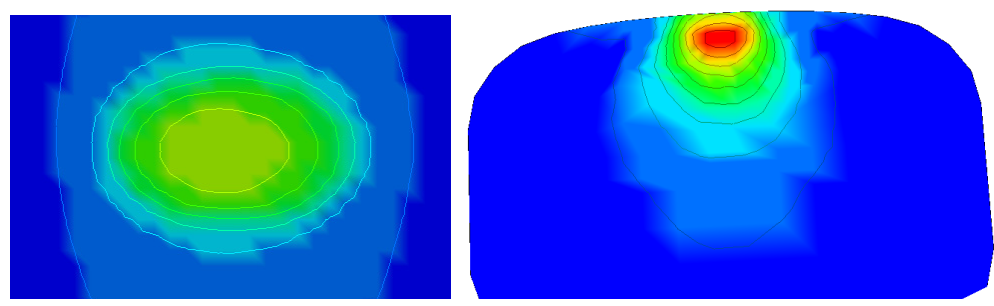

Fringe Levels

(b) Wet contact, $\mathrm{S}_{\mathrm{r}}=1 \%$
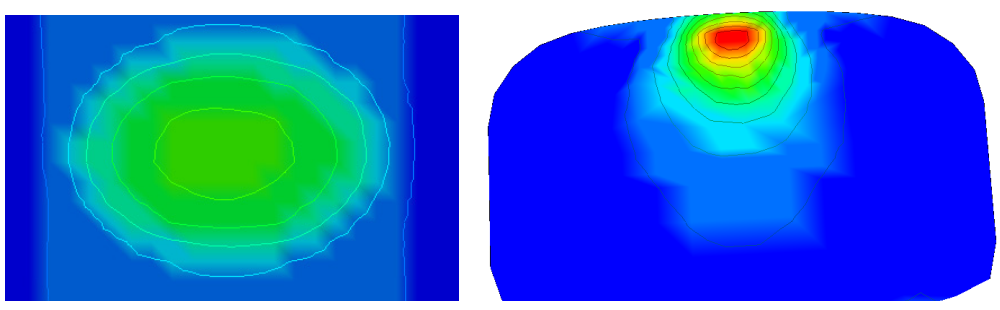

Fringe Levels

(c) Oily contact, $\mathrm{S}_{\mathrm{r}}=1 \%$

Figure 3: Von-Mises stress distribution on the rail surface and cross section.

\subsection{Temperature distribution on rail}

Using the analytical method introduced in section 3, the results of temperature rising on and below the rail surface are shown in figs. 4 and 5 . The calculated results have been compared to those from [15] and found that the results are in good agreement.

From the calculation, it should be noticed that the maximum temperature can be found at the trailing edge of the contact patch $(\mathrm{x} / \mathrm{a}=1)$, and the values of temperature decrease gradually from the trailing edge to the leading edge. The 
same tendency can also be found below the rail surface with a reduced low temperature from the rail surface. Under the wet and oily contact conditions, the maximum values of temperature on the rail surface are $64^{\circ} \mathrm{C}$ and $22^{\circ} \mathrm{C}$, respectively. Moreover, temperature penetrates a very thin layer on the contact surface $(0.113 \mathrm{~mm})$.

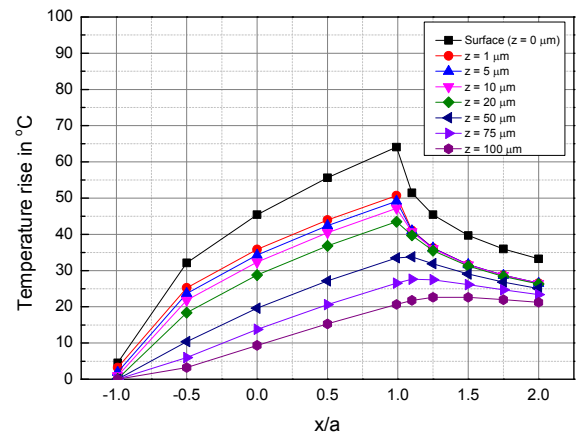

(a) Wet contact

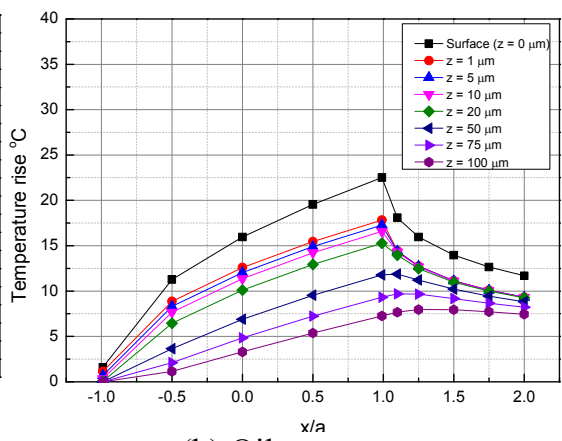

(b) Oily contact

Figure 4: Temperature distribution on rail under wet and oily contact $($ slip rate $=1 \%)$.

In the dry contact condition, however, the temperature is found higher. The maximum temperature under the dry contact condition can reach $128^{\circ} \mathrm{C}$. As shown in the fig. 5, the maximum temperature produced by friction can be increased from $128^{\circ} \mathrm{C}$ to $624^{\circ} \mathrm{C}$ when slip rate increases from $1 \%$ to $5 \%$. Beneath the rail surface, the temperature in the case of $5 \%$ slip rate is also higher than that in the case of $1 \%$ slip rate. For instance, at the depth of $50 \mu \mathrm{m}$, the temperature is found as high as $326^{\circ} \mathrm{C}$ in the case of $5 \%$ slip rate, but it is only $67^{\circ} \mathrm{C}$ if slip rate is set at $1 \%$.

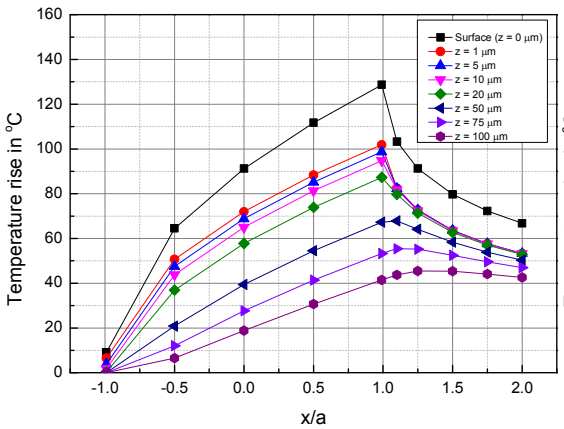

(a) Slip rate $=1 \%$

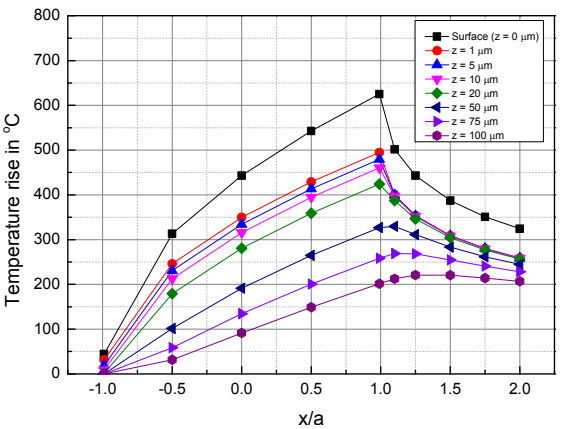

(b) Slip rate $=5 \%$

Figure 5: Temperature distribution under dry contact. 
The influence of temperature on the reduction of the yield strength is illustrated in fig. 6. At the beginning of cycle, the temperature rises when the wheel makes a contact with the rail. If the temperature at the contact zone surpasses $250^{\circ} \mathrm{C}$, the yield strength of material decreases. Once the wheel passes over, the rail is cooled down and the yield strength can retrieve to its previous values. Alternatively, if the stresses exerted on the rail are high enough to cause plastic strain during the cycle, the rail material can be hardened up. On the next cycle, the temperature of the rail rises again; and the softening and hardening processes are iterated. These processes occur over many cycles until the material fail.

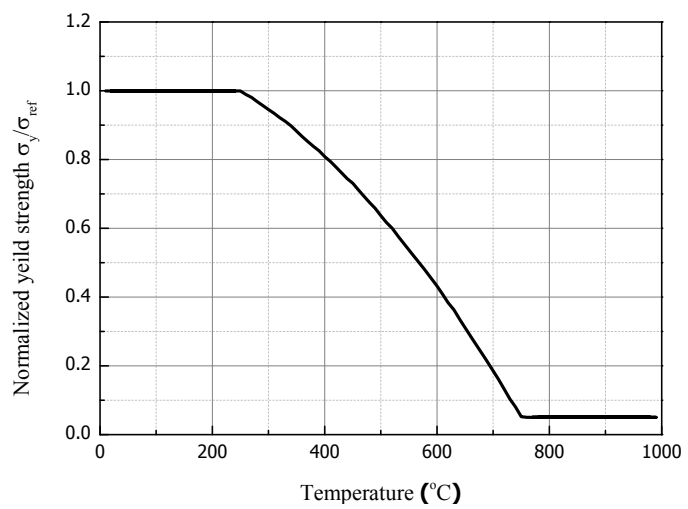

Figure 6: The reduction of yield stress due to temperature rise [20].

Under the above contact conditions (slip rate $=1 \%$, dry, wet and oily), the temperature rise is small (below $250^{\circ} \mathrm{C}$ ); the material, therefore, has not been softening. However, the temperature in the case of $5 \%$ slip rate can be increased to more than $600^{\circ} \mathrm{C}$ which is close to the threshold to generate the white etching layer (temperature to generate WEL is $700^{\circ} \mathrm{C}[8]$ ). Moreover, the yield strength of material would be decreased in this case. After a certain number of continuous loading, the temperature may exceed $700^{\circ} \mathrm{C}$ [21], and cracks can be initiated within the white etching layer due to its brittle behaviour when a traction is present [6].

\section{Conclusion}

A combined tool of numerical FEM method of wheel/rail contact and analytical thermal model of rail temperature variation has been introduced in this paper to calculate the stress states and to predict the temperature rising under a variety of contact conditions (dry, wet and oily). The main conclusions obtained from this work are as follows:

- The environmental condition has a minor effect on the contact pressure and contact area, whereas shear stress has been significantly influenced. 
The higher friction, the higher traction force and shear stress can be generated.

- In dry contact, the maximum Von-Mises stress exerts to rail surface but only rail material beneath the surface is subjected to the maximum VonMises stress in wet and oily contact. Hence surface damage is likely to appear in dry contact, and sub-surface damages can be happened in the wet and oily contact.

- When the slip rate is $1 \%$, the magnitude of temperature is found the highest in dry contact, but not high enough to reduce the material strength and create the white etching layer.

- The higher slip rate, the higher temperature can be exerted on and below the rail surface, which may cause the White Etching Layer generated on the contact surface after a certain number of continuous loading.

\section{Acknowledgement}

This work has been conducted as part of the Cooperative Research Centre (CRC) for Rail Innovation project no. R3.119. The authors would like to thank CRC for financial support.

\section{References}

[1] S. Iwnicki, Handbook of railway vehicle dynamics. Boca Raton: Taylor \& Francis, 2006.

[2] H. Harrison, T. McCanney, and J. Cotter, Recent developments in coefficient of friction measurements at the rail/wheel interface, Wear, vol. 253, pp. 114-123, 2002.

[3] U. Olofsson and T. Telliskivi, Wear, plastic deformation and friction of two rail steels - a full-scale test and a laboratory study, Wear, vol. 254, pp. 80-93, 2003.

[4] A. Rovira, A. Roda, R. Lewis, and M. B. Marshall, Application of Fastsim with variable coefficient of friction using twin disc experimental measurements, Wear, vol. 274-275, pp. 109-126, 2012.

[5] I. M. Widiyarta, U. o. N. u. T. S. o. Mechanical, and S. Engineering, Simulation of Wear and Crack Initiation in Line Contact with Thermal Stresses: University of Newcastle upon Tyne, 2010.

[6] R. I. Carroll and J. H. Beynon, Rolling contact fatigue of white etching layer: Part 1: Crack morphology, Wear, vol. 262, pp. 1253-1266, 2007.

[7] R. I. Carroll and J. H. Beynon, Rolling contact fatigue of white etching layer: Part 2. Numerical results, Wear, vol. 262, pp. 1267-1273, 2007. 
[8] W. Lojkowski, M. Djahanbakhsh, G. Bürkle, S. Gierlotka, W. Zielinski, and H. J. Fecht, Nanostructure formation on the surface of railway tracks, Materials Science and Engineering: A, vol. 303, pp. 197-208, 2001.

[9] T. Kato, A. Sugeta, and E. Nakayama, Investigation of influence of white layer geometry on spalling property in railway wheel steel, Wear, vol. 271, pp. 400-407, 2011.

[10] Ansys Theory Reference for the Mechanical APDL and Mechanical Applications: ANSYS, Inc., 2009.

[11] ESR 0001-G RSU APPENDIX G DRAWINGS, ed: Engineering Standard Rolling Stock, Jun 2010.

[12] AS 1085.1-2002/Amdt 1-2005 : Railway track materials - Steel rails, ed: Standards Australia, 2005.

[13] ESC 230 Sleeper and track support, ed: RailCorp Engineering Standard, 2012.

[14] K. D. Vo, A. K. Tieu, H. T. Zhu, and P. B. Kosasih, A 3D dynamic model to investigate wheel-rail contact under low and high adhesion conditions, Submitted to International Journal of Mechanical Sciences, 2013.

[15] I. M. Widiyarta, F. J. Franklin, and A. Kapoor, Modelling thermal effects in ratcheting-led wear and rolling contact fatigue, Wear, vol. 265, pp. 1325-1331, 2008.

[16] M. Ertz and K. Knothe, A comparison of analytical and numerical methods for the calculation of temperatures in wheel/rail contact, Wear, vol. 253, pp. 498-508, 2002.

[17] S. Simson and S. Mohan, Temperature calculations for rails under frictional contact - Progress report on R3-105, CRC for Rail Innovation , December, 2009.

[18] http://www.kalkersoftware.org/.

[19] K. D. Vo, A. K. Tieu, H. T. Zhu, and P. B. Kosasih, Rolling contact stress states of two contact points on curved track presented at the World Congress on Railway Research 2013, Sydney, Australia, 2013.

[20] A. M. S. Asih, K. Ding, and A. Kapoor, Modelling rail wear transition and mechanism due to frictional heating, Wear, vol. 284-285, pp. 82-90, 2012.

[21] V. Gupta, G. T. Hahn, P. C. Bastias, and C. A. Rubin, Calculations of the frictional heating of a locomotive wheel attending rolling plus sliding, Wear, vol. 191, pp. 237-241, 1996. 